\title{
A novel nomogram based on SEER database for the prediction of liver metastasis in patients with small-cell lung cancer
}

\author{
Yu-Jie Lu ${ }^{1 \#}$, Yi Yang ${ }^{2 \#}$, Yi-Hang Yuan ${ }^{1 \#}$, Wen-Jie Wang ${ }^{3}$, Meng-Ting Cui ${ }^{1}$, Hai-Ying Tang ${ }^{4}$, \\ Wei-Ming Duan ${ }^{1}$
}

${ }^{1}$ Department of Oncology, ${ }^{2}$ Department of Gastroenterology, the First Affiliated Hospital of Soochow University, Suzhou, China; ${ }^{3}$ Department of Radio-Oncology, The Affiliated Suzhou Hospital of Nanjing Medical University, Suzhou, China; ${ }^{4}$ Department of Geriatric Medicine, the First Affiliated Hospital of Soochow University, Suzhou, China

Contributions: (I) Conception and design: WM Duan, HY Tang, YJ Lu; (II) Administrative support: WM Duan, HY Tang; (III) Provision of study materials or patients: YJ Lu, YH Yuan; (IV) Collection and assembly of data: YJ Lu, Y Yang, WJ Wang; (V) Data analysis and interpretation: YJ Lu, Y Yang, MT Cui; (VI) Manuscript writing: All authors; (VII) Final approval of manuscript: All authors.

"These authors contributed equally to this work.

Correspondence to: Wei-Ming Duan, MD. Department of Oncology, the First Affiliated Hospital of Soochow University, Suzhou 215006, China. Email: wmduan@suda.edu.cn; Dr. Hai-Ying Tang. Department of Geriatric Medicine, the First Affiliated Hospital of Soochow University, Suzhou 215006, China. Email: thying0919@163.com.

Background: To establish and validate a nomogram to predict liver metastasis in patients with small-cell lung cancer (SCLC).

Methods: Information on patients diagnosed with SCLC between 2010 and 2015 was retrospectively retrieved from the Surveillance, Epidemiology, and End Results (SEER) database. Risk factors for liver metastasis were identified by logistic regression analyses to construct a nomogram. The predictive accuracy was evaluated by concordance indexes (c-index) and calibration plots, and the comparison of discrimination between the nomogram and other routine staging systems was achieved with the area under receiver operating characteristic curve (AUC) analysis. Decision curve analysis (DCA) was performed to measure the clinical performance of the nomogram.

Results: A total of 12,957 patients met our inclusion criteria and were randomly assigned to training $(\mathrm{n}=6,479)$ and validation $(n=6,478)$ sets. The nomogram which was established based on independent clinicopathological factors had poor accuracy, and after other distant metastatic sites were added into the predictive model, the new nomogram displayed better discrimination power, with c-indexes of 0.703 in the training set and 0.712 in the validation set. Both internal and external calibration plots approached 45 degrees. The AUCs and net benefit of the predictive model were both higher than those of routine staging systems.

Conclusions: The validated nomogram might be a practical tool for clinicians to quantify the risk of liver metastasis in patients with SCLC and improve cancer management.

Keywords: Small-cell lung cancer (SCLC); liver metastasis; Surveillance, Epidemiology, and End Results (SEER); nomogram; validation

Submitted Apr 04, 2020. Accepted for publication Jun 18, 2020.

doi: 10.21037/apm-20-886

View this article at: http://dx.doi.org/10.21037/apm-20-886 


\section{Introduction}

Small-cell lung cancer (SCLC) accounts for approximately $15 \%$ of all lung cancer which is ranked as the first leading cause of cancer-related mortality (1), with an estimated 228,150 new cases and 142,670 mortalities in the USA in 2019 (2). As an aggressive cancer of neuroendocrine origin, SCLC is strongly associated with cigarette smoking (3). Because of lacking early symptoms and highly invasive biological properties, SCLC may spread to the other organs rapidly which may lead to the difficulty of surgical operation compared to non-small cell lung cancer (4). SCLC could be generally divided into two stages, limited and extensive which largely determines the treatment strategies and prognoses (5). Although it is commonly very chemosensitive initially, it almost always recurs after a period of response because of metastasis (6). Thus, as one of the most common metastases of SCLC, liver metastasis is an essential basis when doctors developing various treatment approaches including chemoradiotherapy or immunotherapy, which could bring patients better survival, compared with the standard chemotherapeutic treatment alone (7). Therefore it is imperative for clinicians to make an accurate assessment of the risk of liver metastasis for optimal therapeutic selection.

Recent reviews revealed that there were some relations between clinical factors and the predisposition of liver metastasis in patients with SCLC $(8,9)$. However, most of them lacked the support of the large-cohort and only evaluated the partial criteria. Given the various clinical characteristics of different patients with SCLC, especially those with the metastasis, it is urgent that establishing a more easy and sensitive pretreatment model of evaluations which could better improve the results of the traditional methods, thus improving the outcome of the SCLC. In this study, we aimed to predict the independent factors of SCLC with liver metastasis. Meanwhile, distinguishing from the traditional chart type, we established a model that could bring a faster, more intuitive and accurate display. For this reason, it may be validated prior to clinical use and guiding clinical decision making.

We present the following article in accordance with the TRIPOD Checklist (available at http://dx.doi.org/10.21037/ apm-20-886).

\section{Methods}

\section{Patients and inclusion criteria}

The retrospective study was based on the Surveillance,
Epidemiology, and End Results (SEER) program which covers approximately $30 \%$ of the total US population (10). The records of patients diagnosed with SCLC between 2010 and 2015 were extracted from the database 'SEER 18 Regs Research Data + Hurricane Katrina Impacted Louisiana Cases (1973-2015)' by using SEER*stat 8.3.5 software. The International Classification of Diseases for Oncology third edition (ICD-O-3) was used to identify SCLC by site codes [8002, 8041, 8043, 8144, 8145]. The inclusion criteria were as follows: (I) SCLC was the only primary cancer; (II) age at diagnosis was or older than 18 years; (III) diagnostic confirmation was based on pathological analysis; (IV) clinicopathologic information (i.e., age, sex, race, primary tumor site, tumor size, $\mathrm{N}$ stage, metastasis status, marital status, household income and insurance) of patients was available and known. In this study, all information from the SEER program is available and free for public, so the agreement of the medical ethics committee board was not necessary.

\section{Study variables}

Several variables, such as age, sex, race, primary tumor site, tumor size, $\mathrm{N}$ stage, bone metastasis, brain metastasis, lung metastasis, marital status, insurance and household income, were extracted. Age as a continuous variable was transformed into a categorical variable based on the median value of 65 years. Tumor site was categorized as the main bronchus, upper lobe, middle lobe, lower lobe and overlapping. Information about tumor size was collected through staging scheme version 0204. According to the AJCC $8^{\text {th }}$ TNM Classification of SCLC, the diameter of tumor $\leq 3 \mathrm{~cm}$ was classified as T1, $3-5 \mathrm{~cm}$ were classified as $\mathrm{T} 2,5-7 \mathrm{~cm}$ were classified as $\mathrm{T} 3$, and $>7 \mathrm{~cm}$ were classified as T4 (11). Thus, patients were divided into four groups based on the criterion mentioned above. Similarly, we divide the cases into subgroups according to the $\mathrm{N}$ stage of $\mathrm{N} 0$, $\mathrm{N} 1, \mathrm{~N} 2$ and $\mathrm{N} 3$ based on the newest AJCC $8^{\text {th }} \mathrm{N}$ staging system of lung cancer (12). Records of cancer metastasis status was collected in the SEER database from 2010, and liver metastasis was set as the outcome variable in this study. Meanwhile, several background characteristics, such as marital status, insurance and household income, were also set as the categorical variables.

\section{Construction and validation of nomograms}

To construct a nomogram, half of the patients were 
randomly assigned to a training set, and the rest were randomly assigned to a validation set. Univariate logistic regression analysis was used to evaluate variables in predicting liver metastasis for patients with SCLC. Variables with $\mathrm{P}$ value $<0.05$ after univariate analysis were further analyzed by multivariate logistic regression analysis to obtain the independent factors. A model for predicting the risk of liver metastasis was then virtualized by the nomogram based on these independent variables. Discrimination and calibration, as two main aspects of the performance of models, were used to validate the nomogram in both training set and validation set. We used the concordance index (c-index) to evaluate the predictive accuracy of the model (13). Calibration curves were created to show the relationship between actual probability and the predicted probability. A bootstrapping method with 1,000 resamples was used to reduce the over-fitting. Meanwhile, the receiver operating characteristic (ROC) curves were drawn to compare predictive accuracy between different models by calculating the area under ROC (AUC) (14). In addition, the clinical value of the model was evaluated by decision curve analysis (DCA) (15).

\section{Other statistical analysis}

Student's $t$-test was used to analyze continuous clinical characteristics, and Chi-square test was used to compare categorical data among different groups. Log-rank test and Kaplan-Meier method were used to compare the prognosis between the groups, and the multivariable Cox regression model was applied to analyze the independent variables for overall survivial. All these statistical methods, including logistic regression analysis, were performed by SPSS Statistics software (version 23.0, SPSS Inc., Chicago, USA). Rondom grouping, nomogram, c-index, calibration plot, ROC and DCA were all constructed by the relevant packages (i.e., caret, rms, Hmisc, ROCR and rmda) in R language software (version 3.51, Institute for Statistics and Mathematics, Vienna, Austria). A two-sided P value $<0.05$ was deemed statistically significant.

\section{Results}

\section{Patient characteristics}

A total of 35,902 SCLC patients diagnosed from 2010 to 2015 were collected from the SEER database. After excluding 8,249 patients that SCLC was not the only primary cancer, 5,197 patients who were not diagnosed by pathological analysis and 9,499 patients with unknown clinical pathology information, 12,957 eligible cases were obtained eventually; 6,479 cases were randomly allocated to the training set and 6,478 cases to the validation set. The clinical characteristics of patients in both sets were displayed in Table 1. In the present study, the median age of the total cohort was 65 years old, and the average was 66.80 years. Liver metastasis occurred in 2,004 patients in the training set and 1,914 patients in the validation set. There was no statistically significant difference in the liver metastasis rate between the two cohorts $(\mathrm{P}=0.086$, Table 1$)$. The other $\mathrm{p}$ values were all lager than 0.05 , so there were no significant differences between the two cohorts. After Chi-square test, seven variables, including sex, race, tumor site, tumor size, $\mathrm{N}$ stage, bone metastasis, brain metastasis and lung metastasis, were significantly correlated $(\mathrm{P}<0.05)$ with liver metastasis in the training set (Table 2).

\section{Independent variables}

In model 1 , sex, race, tumor site, tumor size and $\mathrm{N}$ stage, considered to be associated with liver metastasis after univariate logistic regression analysis, and then were put into the multivariate analysis (model 1, Table 3). Four factors were related to liver metastasis: sex [female: odds ratio (OR) 0.798, 95\% CI, 0.716-0.888, $\mathrm{P}<0.001]$, race (black: OR 0.681, 95\% CI, 0.560-0.827, $\mathrm{P}<0.001$; other: OR $0.613,95 \%$ CI, $0.460-0.819, \mathrm{P}=0.001)$, tumor size $(3-5 \mathrm{~cm}$ : OR 1.158, 95\% CI, 1.001-1.341, $\mathrm{P}=0.048 ; 5-7 \mathrm{~cm}$ : OR $1.210,95 \% \mathrm{CI}, 1.033-1.418, \mathrm{P}=0.018$; $>7 \mathrm{~cm}$ : OR 0.901, 95\% CI, 0.773-1.050, $\mathrm{P}=0.182)$ and $\mathrm{N}$ stage $(\mathrm{N} 1$ : OR 1.444, 95\% CI, 1.121-1.861, P=0.004; N2: OR 2.203, 95\% CI, 1.858-2.612, $\mathrm{P}<0.001$; N3: OR 2.228, 95\% CI, 1.835-2.705, $\mathrm{P}<0.001)$. In model 2 , the other three metastatic sites were added into the predictive system, and eventually two of them were independently related to liver metastasis after multivariate analysis (model 2, Table 3). Six variables were considered as independent predictive factors: sex (female: OR $0.868,95 \%$ CI, $0.774-0.972, \mathrm{P}=0.015$ ), race (black: OR 0.715, 95\% CI, 0.583-0.876, $\mathrm{P}=0.001$; other: OR 0.660, 95\% CI, 0.487-0.893, $\mathrm{P}=0.007)$, tumor size ( $3-5 \mathrm{~cm}$ : OR 1.054, 95\% CI, 0.903-1.229, $\mathrm{P}=0.506$; 5-7 cm: OR 1.131, 95\% CI, 0.957-1.337, $\mathrm{P}=0.015$; $>7 \mathrm{~cm}$ : OR $0.812,95 \% \mathrm{CI}$, 0.691-0.955, $\mathrm{P}=0.012$ ), $\mathrm{N}$ stage (N1: OR $1.283,95 \% \mathrm{CI}$, $0.985-1.670, \mathrm{P}=0.065$; N2: OR 1.823, 95\% CI, 1.528-2.176, $\mathrm{P}<0.001$; N3: OR 1.569, 95\% CI, 1.279-1.925, $\mathrm{P}<0.001$ ), bone metastasis (yes: OR 4.305, 95\% CI, 3.799-4.878, 
Table 1 Demographic and clinical variables of patients with smallcell lung cancer

\begin{tabular}{|c|c|c|c|c|}
\hline \multirow[b]{2}{*}{ Variables } & \multicolumn{3}{|c|}{ SEER cohort $(n=12,957)$} & \multirow[t]{2}{*}{$P$ value } \\
\hline & $\begin{array}{l}\text { Total } \\
\text { cohort }\end{array}$ & $\begin{array}{l}\text { Training } \\
(n=6,479)\end{array}$ & $\begin{array}{l}\text { Validation } \\
(n=6,478)\end{array}$ & \\
\hline $\begin{array}{l}\text { Age (mean), } \\
\text { year }\end{array}$ & 66.80 & 66.75 & 66.86 & 0.400 \\
\hline \multicolumn{5}{|l|}{ Sex } \\
\hline Male & 6,490 & 3,298 & 3,192 & 0.064 \\
\hline Female & 6,467 & 3,181 & 3,286 & \\
\hline \multicolumn{5}{|l|}{ Race } \\
\hline White & 11,171 & 5,571 & 5,600 & 0.110 \\
\hline Black & 1,201 & 630 & 571 & \\
\hline Other* & 585 & 278 & 307 & \\
\hline \multicolumn{5}{|l|}{ Tumor site } \\
\hline $\begin{array}{l}\text { Main } \\
\text { bronchus }\end{array}$ & 1,537 & 793 & 744 & 0.241 \\
\hline Upper lobe & 7,540 & 3,774 & 3,766 & \\
\hline Middle lobe & 600 & 290 & 310 & \\
\hline Lower lobe & 3,085 & 1,537 & 1,548 & \\
\hline Overlapping & 195 & 85 & 110 & \\
\hline \multicolumn{5}{|l|}{$\begin{array}{l}\text { Tumor size } \\
\text { (cm) }\end{array}$} \\
\hline$\leq 3$ & 3,650 & 1,826 & 1,824 & 0.711 \\
\hline$>3$ and $\leq 5$ & 3,411 & 1,717 & 1,694 & \\
\hline$>5$ and $\leq 7$ & 2,607 & 1,278 & 1,329 & \\
\hline$>7$ & 3,289 & 1,658 & 1,631 & \\
\hline \multicolumn{5}{|l|}{ N (8th) } \\
\hline No & 2,177 & 1,059 & 1,118 & 0.525 \\
\hline $\mathrm{N} 1$ & 1,022 & 512 & 510 & \\
\hline N2 & 7,162 & 3,614 & 3,548 & \\
\hline N3 & 2,596 & 1,294 & 1,302 & \\
\hline \multicolumn{5}{|l|}{ Marital status } \\
\hline Married & 6,715 & 3,390 & 3,325 & 0.257 \\
\hline Unmarried & 6,242 & 3,089 & 3,153 & \\
\hline \multicolumn{5}{|l|}{ Insurance } \\
\hline Insured & 12,488 & 6,240 & 6,248 & 0.673 \\
\hline Uninsured & 469 & 239 & 1,230 & \\
\hline
\end{tabular}

Table 1 (continued)
Table 1 (continued)

\begin{tabular}{|c|c|c|c|c|}
\hline \multirow[b]{2}{*}{ Variables } & \multicolumn{3}{|c|}{ SEER cohort $(n=12,957)$} & \multirow[t]{2}{*}{$P$ value } \\
\hline & $\begin{array}{l}\text { Total } \\
\text { cohort }\end{array}$ & $\begin{array}{c}\text { Training } \\
(\mathrm{n}=6,479)\end{array}$ & $\begin{array}{l}\text { Validation } \\
(n=6,478)\end{array}$ & \\
\hline \multicolumn{5}{|l|}{$\begin{array}{l}\text { Household } \\
\text { income }\end{array}$} \\
\hline$\leq 6,000 \$$ & 6,504 & 3,229 & 3,275 & 0.414 \\
\hline$>6,000 \$$ & 6,453 & 3,250 & 3,203 & \\
\hline \multicolumn{5}{|l|}{$\begin{array}{l}\text { Bone } \\
\text { metastasis }\end{array}$} \\
\hline No & 9,923 & 4,949 & 4,974 & 0.593 \\
\hline Yes & 3,034 & 1,530 & 1,504 & \\
\hline \multicolumn{5}{|l|}{$\begin{array}{l}\text { Brain } \\
\text { metastasis }\end{array}$} \\
\hline No & 10,706 & 5,342 & 5,364 & 0.597 \\
\hline Yes & 2,251 & 1,137 & 1,114 & \\
\hline \multicolumn{5}{|l|}{$\begin{array}{l}\text { Liver } \\
\text { metastasis }\end{array}$} \\
\hline No & 9,039 & 4,475 & 4,564 & 0.086 \\
\hline Yes & 3,918 & 2,004 & 1,914 & \\
\hline \multicolumn{5}{|l|}{$\begin{array}{l}\text { Lung } \\
\text { metastasis }\end{array}$} \\
\hline No & 11,267 & 5,654 & 5,613 & 0.295 \\
\hline Yes & 1,690 & 825 & 865 & \\
\hline
\end{tabular}

*, other includes Native American/Alaska native, Asian/Pacific Islander, and unknown.

$\mathrm{P}<0.001$ ) and lung metastasis (yes: OR $1.730,95 \%$ CI, 1.473-2.033, $\mathrm{P}<0.001)$.

\section{Nomograms construction and validation}

Nomogram of model 1 was constructed based on the four independent predictors: sex, race, tumor size and $\mathrm{N}$ stage (Figure 1A). All independent factors after multivariate analysis were all included for the construction of the nomogram of model 2 (Figure $1 B$ ). Unsatisfactorily, the nomogram of model 1 showed ordinary predictive accuracy, with c-indexes of 0.597 (95\% CI, 0.582-0.612, $\mathrm{P}<0.001$ ) in the training set and 0.593 (95\% CI, 0.578-0.608, $\mathrm{P}<0.001)$ in the validation set. The internal and external calibration curves were shown in Figure 2. Compared 
Table 2 Relationship between clinicopathological factors and liver metastasis in the training and validation cohorts

\begin{tabular}{|c|c|c|c|c|c|c|}
\hline Variables & \multicolumn{3}{|c|}{ Training cohort } & \multicolumn{3}{|c|}{ Validation cohort } \\
\hline Age (mean), year & 66.64 & 67.00 & 0.677 & 66.81 & 66.98 & 0.093 \\
\hline \multicolumn{7}{|l|}{ Sex } \\
\hline Male & 2,204 & 1,094 & $<0.001$ & 2,175 & 1,017 & $<0.001$ \\
\hline \multicolumn{7}{|l|}{ Race } \\
\hline White & 3,781 & 1,790 & $<0.001$ & 3,882 & 1,718 & $<0.001$ \\
\hline Black & 480 & 150 & & 443 & 128 & \\
\hline Other* $^{*}$ & 214 & 64 & & 239 & 68 & \\
\hline Upper lobe & 2,666 & 1,108 & & 2,680 & 1,086 & \\
\hline Middle lobe & 208 & 82 & & 237 & 73 & \\
\hline Lower lobe & 1,036 & 501 & & 1,049 & 499 & \\
\hline Overlapping & 57 & 28 & & 74 & 36 & \\
\hline \multicolumn{7}{|l|}{ Tumor size (cm) } \\
\hline$\leq 3$ & 1,307 & 519 & $<0.001$ & 1,342 & 482 & 0.006 \\
\hline$>3$ and $\leq 5$ & 1,148 & 569 & & 1,172 & 522 & \\
\hline$>5$ and $\leq 7$ & 836 & 442 & & 930 & 399 & \\
\hline N2 & 2,380 & 1,234 & & 2,389 & 1,159 & \\
\hline N3 & 852 & 442 & & 869 & 433 & \\
\hline \multicolumn{7}{|l|}{ Marital status } \\
\hline Married & 2,320 & 1,070 & 0.248 & 2,291 & 1,034 & 0.005 \\
\hline Unmarried & 2,155 & 934 & & 2,273 & 880 & \\
\hline \multicolumn{7}{|l|}{ Insurance } \\
\hline Insured & 4,319 & 1,921 & 0.196 & 4,400 & 1,848 & 0.773 \\
\hline Uninsured & 156 & 83 & & 164 & 66 & \\
\hline \multicolumn{7}{|l|}{ Household income } \\
\hline$\leq 6,000 \$$ & 2,226 & 1,003 & 0.819 & 2,343 & 932 & 0.052 \\
\hline$>6,000 \$$ & 2,249 & 1,001 & & 2,221 & 982 & \\
\hline
\end{tabular}

Table 2 (continued) 
Table 2 (continued)

\begin{tabular}{|c|c|c|c|c|c|c|}
\hline Variables & \multicolumn{3}{|c|}{ Training cohort } & \multicolumn{3}{|c|}{ Validation cohort } \\
\hline \multicolumn{7}{|c|}{ Bone metastasis } \\
\hline No & 3,834 & 1,115 & $<0.001$ & 3,910 & 1,064 & $<0.001$ \\
\hline Yes & 641 & 889 & & 654 & 850 & \\
\hline No & 3,721 & 1,621 & 0.027 & 3,796 & 1,568 & 0.224 \\
\hline Yes & 754 & 383 & & 768 & 346 & \\
\hline \multicolumn{7}{|c|}{ Lung metastasis } \\
\hline No & 4,026 & 1,628 & $<0.001$ & 4,124 & 1,489 & $<0.001$ \\
\hline
\end{tabular}

*, other includes Native American/Alaska native, Asian/Pacific Islander, and unknown.

with the nomogram of model 1, the one of model 2 demonstrated better accuracy with c-indexes of 0.703 (95\% CI, 0.689-0.717, $\mathrm{P}<0.001$ ) in the training set and 0.712 (95\% CI, 0.698-0.726, $\mathrm{P}<0.001$ ) in the validation set. Both the internal and external calibration curves approached 45 degrees (Figure 2), which indicated the nomogram of model 2 had good calibration performance. Additionally, the relevant scores of each factor in the two nomograms were detailed in Table 4.

\section{Predictive and clinical performance of the nomogram of model 2}

ROC was applied to compare the predictive performance of the nomogram and other risk factors in this study. In the training set, the AUC value of the nomogram of model 2 was 0.694 (95\% CI, $0.680-0.708, \mathrm{P}<0.001$ ), which was significantly larger than those of tumor size $(0.504$, 95\% CI, 0.489-0.519, $\mathrm{P}<0.001)$ and $\mathrm{N}$ stage $(0.559,95 \%$ CI, 0.544-0.574, $\mathrm{P}<0.001$ ) (Figure $3 A$ ). In the validation set, the AUC value of the nomogram $(0.709,95 \% \mathrm{CI}$, $0.695-0.723, \mathrm{P}<0.001)$ was also larger than those of tumor size $(0.523,95 \% \mathrm{CI}, 0.507-0.538, \mathrm{P}<0.001)$ and $\mathrm{N}$ stage (0.563, 95\% CI, 0.548-0.577, $\mathrm{P}<0.001$ ) (Figure 3B). DCA, as a new tool evaluating clinical performance of predictive models, displayed different NBs at each relevant risk. For the training set, the threshold probability of $0.10-0.68$ for liver metastasis was the most beneficial for predicting liver metastasis in patients with the nomogram of model 2.
Compared with tumor size and $\mathrm{N}$ stage, the increased $\mathrm{NB}$ of nomogram showed the nomogram had better clinical predictive accuracy in both sets (Figure $3 C, D$ ). In order to further explore the clinical impact of the nomogram on the daily routine, all patients had been divided into two groups according to the median value of liver metastasis prediction points. Patients with prediction points higher than 86 had worse outcome, and those with lower liver involvement risk had better overall survival $(\mathrm{P}<0.001)$ (Figure 4). Liver metastasis prediction points was defined as a new variable in the total cohort and proved to be an independent prognostic factor in multivariable Cox regression model (Table 5).

\section{Discussion}

Among patients with SCLC diagnosed, most of them had distant metastasis easily, including multiple lung metastases, bone metastasis, brain metastasis and liver metastasis which meant in the advanced stage and also brought difficulty in the choices of therapy $(16,17)$. Meanwhile, some reports revealed that SCLC patients had a higher incidence rate of the liver (61.9\%) compared to other metastasis (18). Moreover, liver metastasis with SCLC displayed a higher mortality risk which was 2.41-fold higher than other distant metastasis $(\mathrm{P}<0.001)(19)$, and was 1.53 -fold higher than brain metastasis $(\mathrm{P}<0.05)(20)$. Hence, liver metastasis still may be considered a negative prognostic factor for SCLC patients. Up to now, computed tomography and magnetic resonance imaging are still the conventional 
Table 3 Risk variables for liver metastasis determined by univariate and multivariate logistic regression analyses

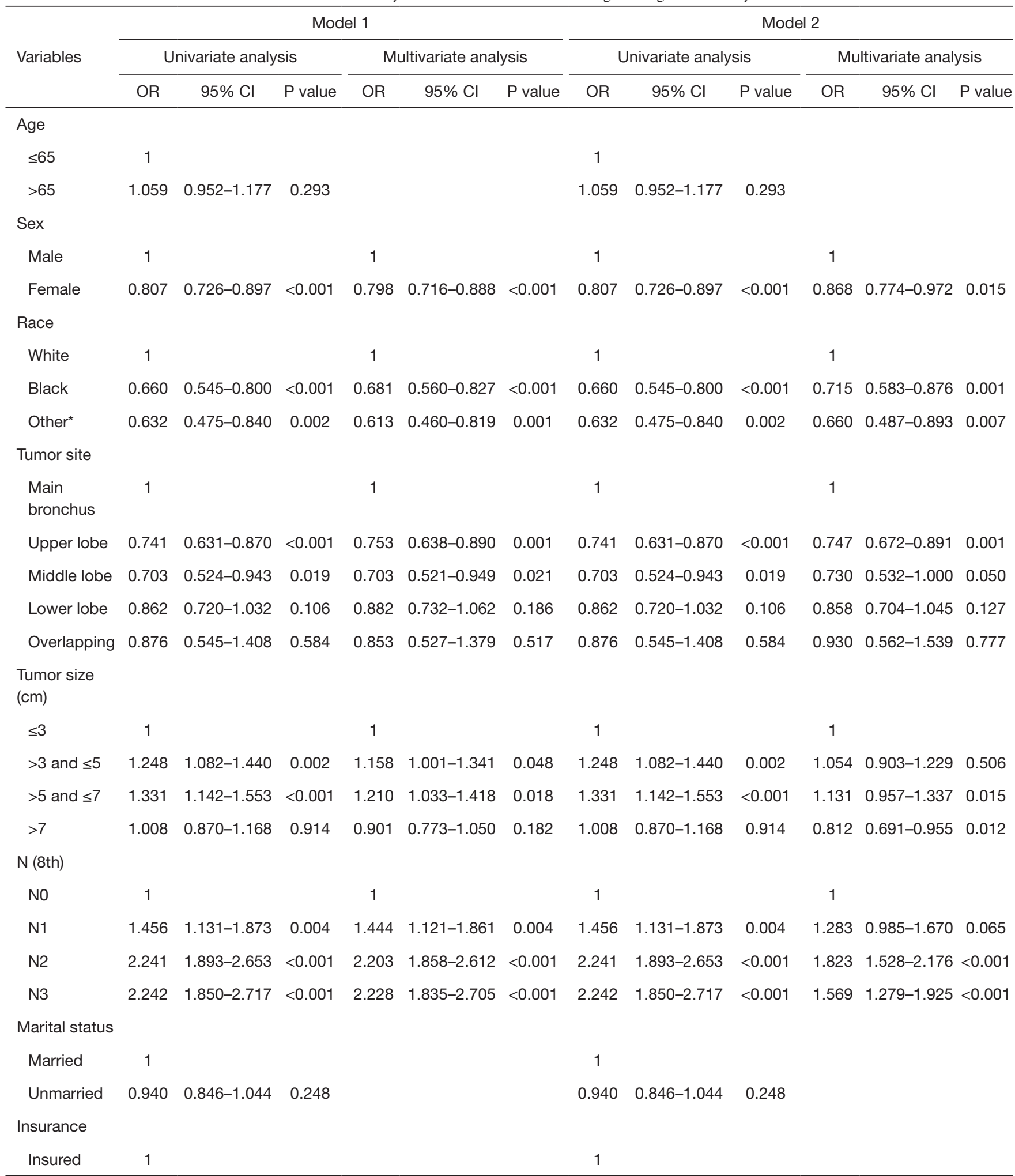

Table 3 (continued) 
Table 3 (continued)

\begin{tabular}{|c|c|c|c|c|c|c|c|c|c|c|c|c|}
\hline \multirow{2}{*}{ Variables } & \multicolumn{6}{|c|}{ Model 1} & \multicolumn{6}{|c|}{ Model 2} \\
\hline & OR & $95 \% \mathrm{Cl}$ & $P$ value & OR & $95 \% \mathrm{Cl}$ & $\mathrm{P}$ value & OR & $95 \% \mathrm{Cl}$ & $P$ value & OR & $95 \% \mathrm{Cl}$ & $P$ value \\
\hline Uninsured & 1.196 & $0.912-1.570$ & 0.196 & & & & 1.196 & $0.912-1.570$ & 0.196 & & & \\
\hline \multicolumn{13}{|l|}{$\begin{array}{l}\text { Household } \\
\text { income }\end{array}$} \\
\hline$>6,000 \$$ & 0.988 & $0.889-1.098$ & 0.819 & & & & 0.988 & $0.889-1.098$ & 0.819 & & & \\
\hline \multicolumn{13}{|l|}{$\begin{array}{l}\text { Bone } \\
\text { metastasis }\end{array}$} \\
\hline No & & & & & & & 1 & & & 1 & & \\
\hline Yes & & & & & & & 1.166 & $1.018-1.336$ & 0.027 & 1.053 & $0.909-1.220$ & 0.492 \\
\hline \multicolumn{13}{|l|}{$\begin{array}{l}\text { Lung } \\
\text { metastasis }\end{array}$} \\
\hline No & & & & & & & 1 & & & 1 & & \\
\hline Yes & & & & & & & 2.071 & $1.785-2.403$ & $<0.001$ & 1.730 & $1.473-2.033$ & $<0.001$ \\
\hline
\end{tabular}

*, other includes Native American/Alaska native, Asian/Pacific Islander, and unknown.

tests of liver metastasis (21), which does not show high sensitivities and specificities in the diagnosis of liver metastasis, especially minor metastasis in patients with SCLC (19). Another common test in the diagnosis of liver metastasis is the increase of tumor markers which although showed the higher sensitivities, could lead to the problems of misdiagnosing (22). Whole-body fluorodeoxyglucose positron emission tomography (FDG-PET) fused with CT (PET/CT) could be more sensitive than CT which excludes $88 \%$ of the metastases (23). However, because of the expensive cost of PET/CT, it may not be suitable for follow-up and diagnosis. Pathologic diagnosis, which was regarded as the golden criterion, is the authentic diagnosis of disease. However, some reports believed that not only biopsy was hard and painful to carry out, but also increased the risk of tumor cells spreading which meant it could not be a safe way for common diagnosis (24). Thus, it is necessary to screen out the high-risk population with distant metastasis for more sensitive and rigorous pretreatment imaging evaluations.
Nomogram, as a significant medical tool, could not only predict the risk of disease or survival outcomes but also help doctors screen high-risk patients and determine appropriate treatment measures $(25,26)$. The predictive model accurately quantified the influence on each risk by integrating a large number of clinicopathological characteristics (27). In this study, a total of 12,957 patients diagnosed with SCLC were collected from the SEER database, and over $30 \%$ of the cases suffered from liver metastasis. Based on univariate and multivariate logistic regression analyses, sex, race, tumor size and $\mathrm{N}$ stage were looked as independent predictors for liver metastasis in patients with SCLC and used to establish a nomogram. However, the c-index of the model was lower than 0.6 , which indicated the predicted probability was not very consistent with the actual one of liver metastasis. Then, we included the other distant metastatic status into the predictive system, and it was gratifying that the new nomogram showed a good discrimination ability. In comparison with other routine staging systems, the new nomogram displayed 


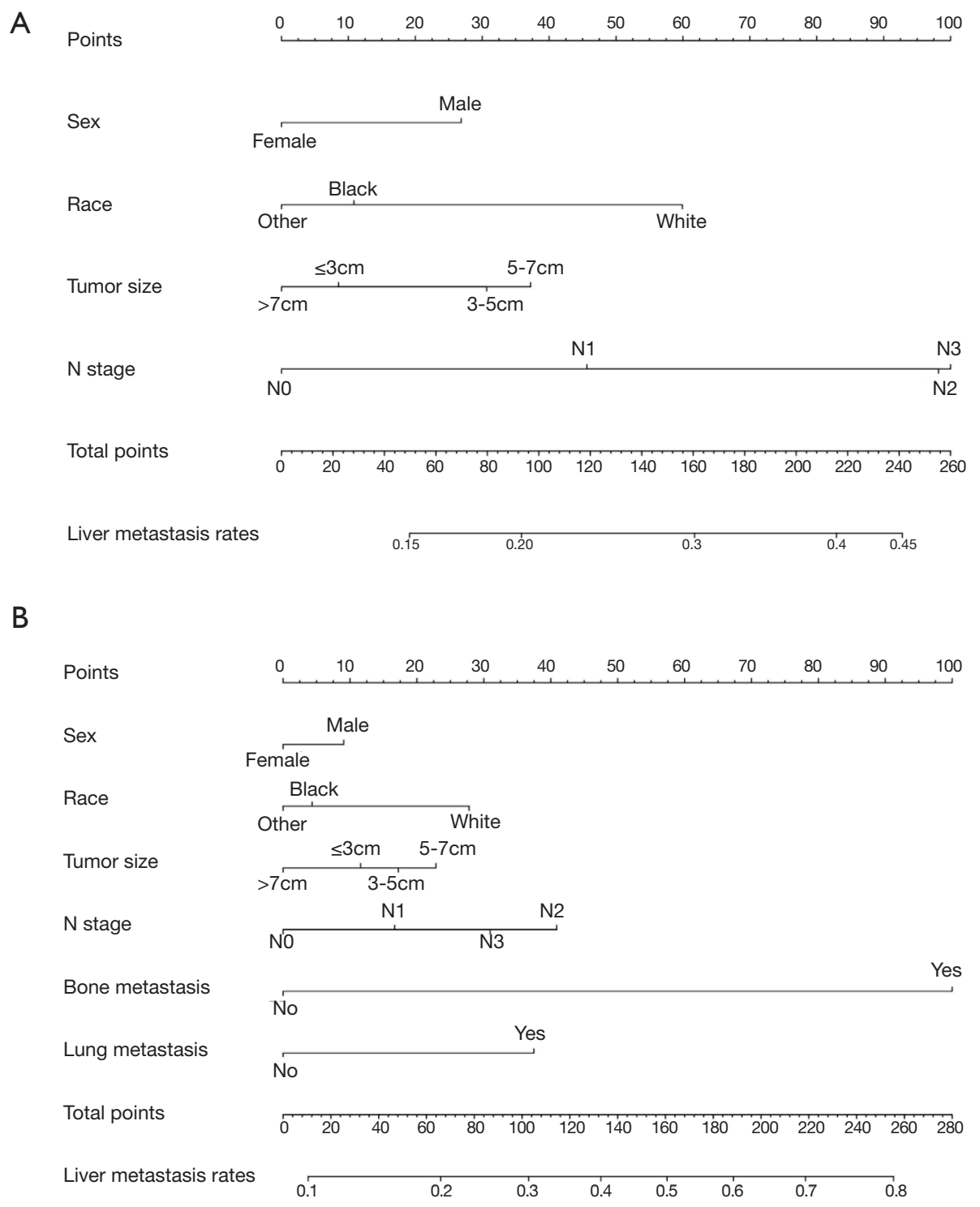

Figure 1 Nomograms for predicting the risk of liver metastasis in patients with small-cell lung cancer. (A) The nomogram of model 1 composed of clinicopathological variables; (B) the nomogram of model 2 composed of the variables in model 2 and the other two organ metastasis sites.

better accuracy in predicting liver metastasis based on ROC analyses. In addition, the method of using the prognostic model is very simple and the consequence is very easy to understand. First, the user can draw a vertical line from each factor to the 'points' line and then add all the 'points' to get the 'total points'. Finally, a vertical line is drawn from 'total points' to the 'liver metastasis rates' and the risk of liver metastasis can be obtained. For example, a white female patient with a tumor size of $4 \mathrm{~cm}$ is diagnosed with $\mathrm{N} 2$ stage, and she has lung metastasis and no bone metastasis at the initial diagnosis. According to the nomogram and the score table, the total points is 123 and the risk of liver metastasis is $38 \%$. Despite this, great discrimination or calibration performance does not equal with the wonderful practicability in clinical work (27). Therefore, DCA was used to estimate the clinical usefulness 

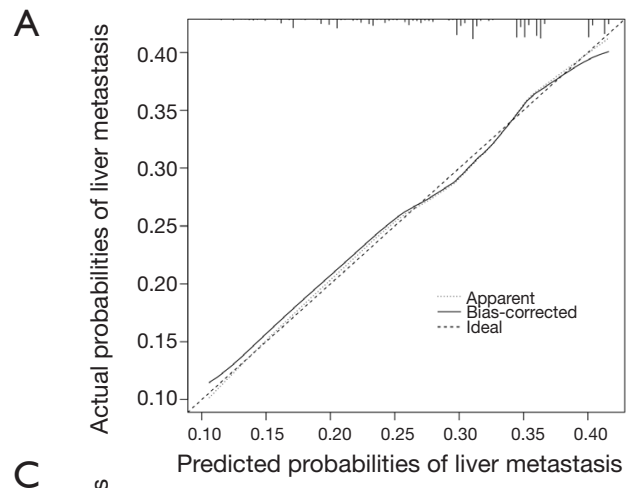

C

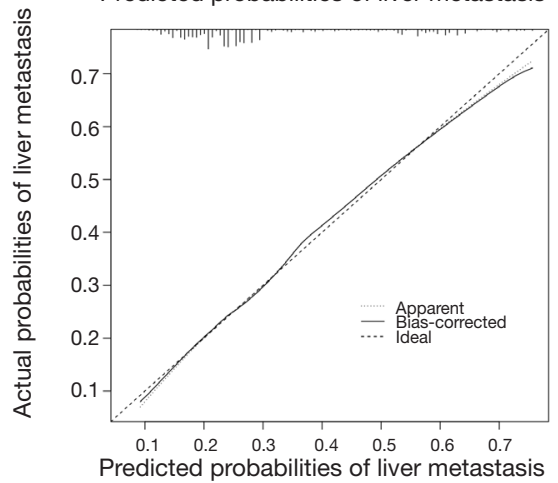

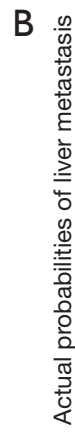
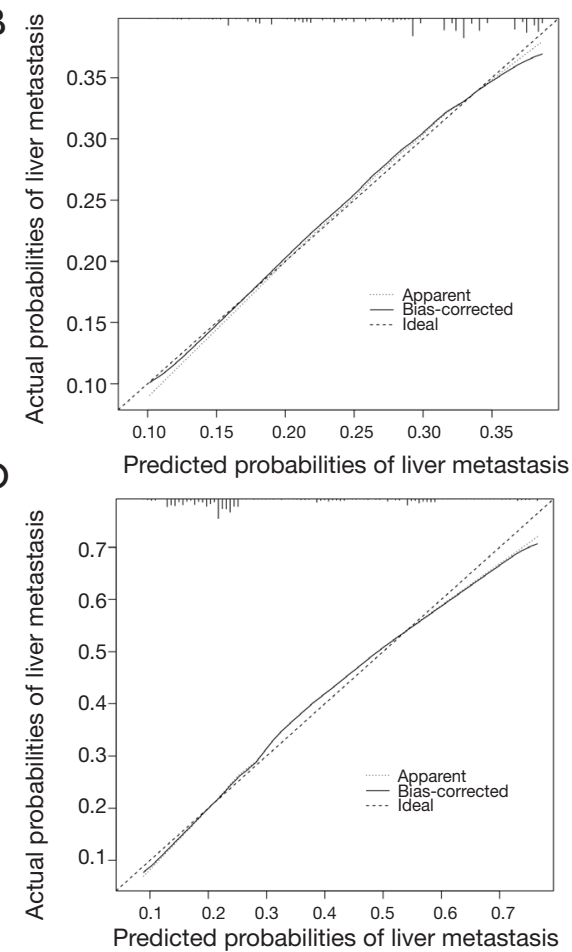

Figure 2 Internal (A) and external (B) calibration plots of the nomogram of model 1. Internal (C) and external (D) calibration plots of the nomogram of model 2.

Table 4 Scores of each relevant factor in the nomograms

\begin{tabular}{|c|c|c|c|}
\hline \multirow{2}{*}{ Variables } & \multirow{2}{*}{ Classification } & \multicolumn{2}{|c|}{ Nomogram score } \\
\hline & & Model 1 & Model 2 \\
\hline \multirow[t]{2}{*}{ Sex } & Male & 27 & 9 \\
\hline & Female & 0 & 0 \\
\hline \multirow[t]{3}{*}{ Race } & White & 60 & 28 \\
\hline & Black & 11 & 4 \\
\hline & Other & 0 & 0 \\
\hline \multirow[t]{4}{*}{ Tumor size (cm) } & $\leq 3$ & 9 & 12 \\
\hline & $>3$ and $\leq 5$ & 31 & 17 \\
\hline & $>5$ and $\leq 7$ & 37 & 23 \\
\hline & $>7$ & 0 & 0 \\
\hline \multirow[t]{4}{*}{ N (8th) } & No & 0 & 0 \\
\hline & N1 & 46 & 17 \\
\hline & N2 & 98 & 41 \\
\hline & N3 & 100 & 31 \\
\hline \multirow[t]{2}{*}{ Bone metastasis } & No & & 0 \\
\hline & Yes & & 100 \\
\hline \multirow[t]{2}{*}{ Lung metastasis } & No & & 0 \\
\hline & Yes & & 37 \\
\hline
\end{tabular}

*, other includes Native American/Alaska native, Asian/Pacific Islander, and unknown. of the new nomogram, and the established predictive model obviously showed better clinical utility than routine staging systems. Also, liver metastasis prediction points that describes the risk of liver metastasis is looked as a new prognostic variable in this study. Those patients with prediction points larger than 86 had a worse prognosis based on our analysis, and clinicians have a responsibility to advise high-risk patients who might not be found have metastasis at the initial diagnosis to take close imaging examinations of the liver later on.

This study illustrated that the correlation existed between clinicopathologic characteristics and liver metastasis in patients with SCLC. Our results demonstrated the men were more likely to experience liver metastasis than the women, which was similar to Lim's finding (28). Smoking, as the main indicator for SCLC, is a common behavior in men, and it may accelerate the progression of SCLC to some extent $(29,30)$. A previous study also suggested male patients with SCLC had a worse prognosis than females (31). Compared with black or other ethnic patients with SCLC, white cases had a shorter overall or cancer-specific survival time (32). In this study, white 
A

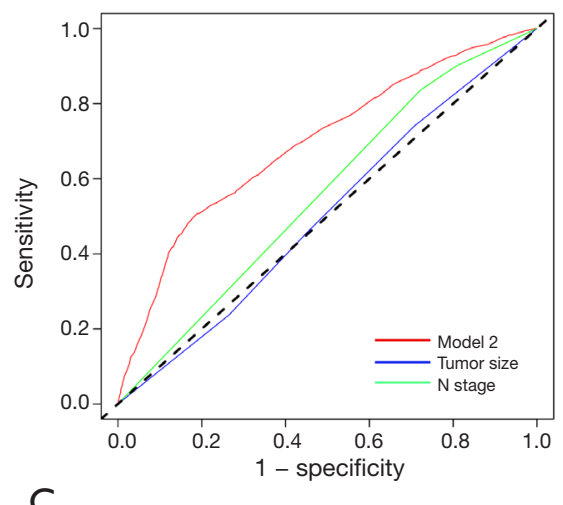

C

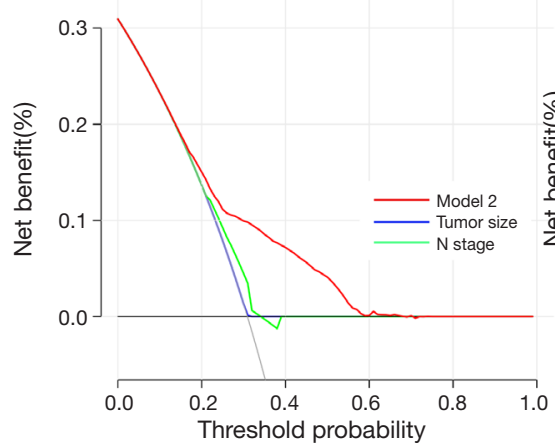

B

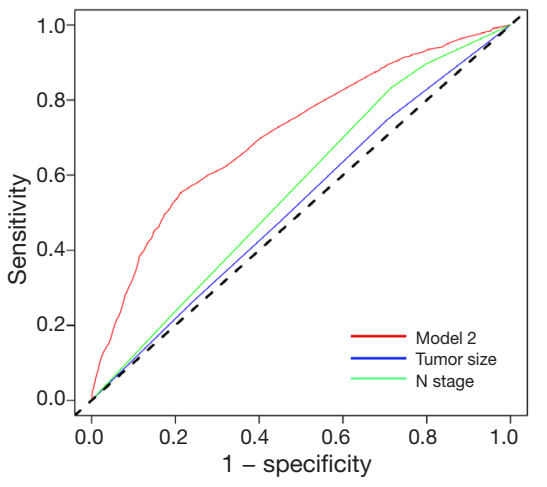

D

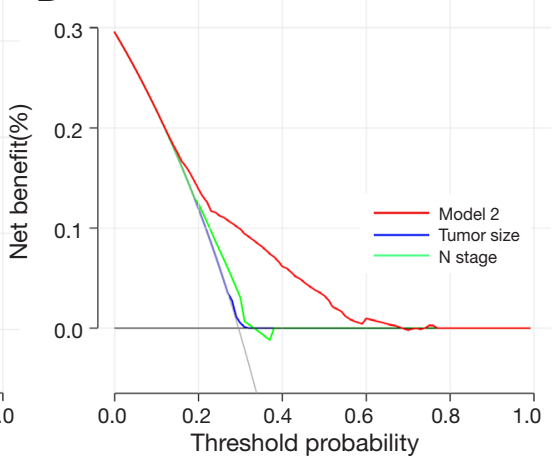

Figure 3 Receiver operating characteristic (ROC) analyses of the nomogram of model 2 and other predictors (tumor size and $\mathrm{N}$ stage) based on the training (A) and validation (B) cohorts. Decision curve analysis (DCA) of the nomogram of model 2 and other predictors (tumor size and $\mathrm{N}$ stage) based on training (C) and validation (D) cohorts. The $\mathrm{x}$-axis and the $\mathrm{y}$-axis were the threshold probability and the net benefit, respectively. The gray line assumes all patients with small-cell lung cancer will suffer from liver metastasis, while the horizontal black line assumes all patients will not experience liver metastasis.

patients had a higher risk of liver metastasis among all races and more research needs to be conducted. It was controversial to common sense that patients with tumor size larger than $7 \mathrm{~cm}$ had the lowest risk of liver metastasis among all cases in our cohort, but it was the same as the result of Li's study (33). The risk of liver metastasis was the highest when the tumor size was between 5 and $7 \mathrm{~cm}$ (OR 1.131, $\mathrm{P}=0.015$ ), and the specific reasons should be explored in further research. As shown in the nomogram, a higher $\mathrm{N}$ stage $(\mathrm{N} 2$ or $\mathrm{N} 3, \mathrm{P}<0.001)$ corresponded to a higher score for predicting liver metastasis, which was consistent with the fact that distant metastases were associated with the number of lymph nodes (34). In this study, almost $60 \%$ of the patients with bone metastasis had simultaneous liver metastasis and about $50 \%$ of the patients with lung metastasis suffered from liver metastasis at the same time. Cai et al. developed a retrospective cohort study and found nearly $42 \%$ patients with extensive SCLC had at least two distant metastasis sites (32). These indicated that SCLC cells might have already metastasized to multiple organs when distant metastases were detected, and patients with bone or lung metastasis were more likely to experience liver metastasis. After the metastatic indicators were included in the predictive system to quantify their influence on liver metastasis, the nomogram displayed better accuracy, and it might be an informed choice to add them into the nomogram.

Although some biomarkers, including CD9 transmembrane protein and Delta-like-4-Notch signaling inhibitor, were confirmed to be associated with the progression of liver metastasis in SCLC $(35,36)$, they could not be put to daily clinical use because of the high cost and inconvenience of examination. The established predictive model was based on several background characteristics 


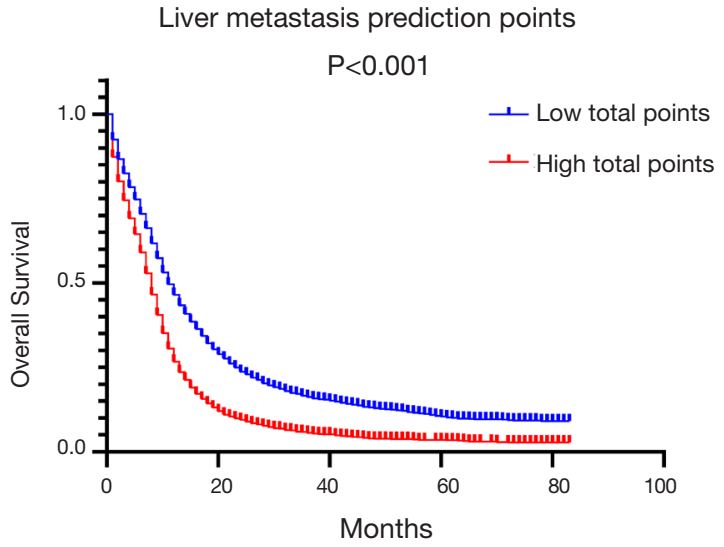

Figure 4 Survival analysis between SCLC patients with low total points and those with high total points. SCLC, small-cell lung cancer.

Table 5 Independent risk variables for overall survival of patients with SCLC

\begin{tabular}{|c|c|c|c|}
\hline \multirow{2}{*}{ Variables } & \multicolumn{3}{|c|}{ Cox regression model } \\
\hline & $\mathrm{HR}$ & $95 \% \mathrm{Cl}$ & $P$ value \\
\hline \multicolumn{4}{|l|}{ Age } \\
\hline$\leq 65$ & Ref & & \\
\hline$>65$ & 1.412 & $1.360-1.466$ & $<0.001$ \\
\hline \multicolumn{4}{|l|}{ Sex } \\
\hline Male & Ref & & \\
\hline Female & 0.861 & $0.828-0.896$ & $<0.001$ \\
\hline \multicolumn{4}{|l|}{ Race } \\
\hline White & Ref & & \\
\hline Black & 0.951 & $0.890-1.016$ & 0.137 \\
\hline Other* $^{*}$ & 0.918 & $0.838-1.006$ & 0.066 \\
\hline \multicolumn{4}{|l|}{ Tumor site } \\
\hline Main bronchus & Ref & & \\
\hline Upper lobe & 0.969 & $0.914-1.028$ & 0.299 \\
\hline Middle lobe & 1.044 & $0.944-1.154$ & 0.399 \\
\hline Lower lobe & 1.054 & $0.987-1.126$ & 0.199 \\
\hline Overlapping & 1.093 & $0.937-1.275$ & 0.256 \\
\hline \multicolumn{4}{|l|}{ Tumor size (cm) } \\
\hline$\leq 3$ & Ref & & \\
\hline$>3$ and $\leq 5$ & 1.189 & $1.130-1.251$ & $<0.001$ \\
\hline
\end{tabular}

Table 5 (continued)

Table 5 (continued)

\begin{tabular}{lccc}
\hline \multirow{2}{*}{ Variables } & \multicolumn{3}{c}{ Cox regression model } \\
\cline { 2 - 4 }$>5$ and $\leq 7$ & 1.185 & $1.119-1.255$ & $<0.001$ \\
$>7$ & 1.329 & $1.260-1.402$ & $<0.001$ \\
N (8th) & & & \\
N0 & Ref & & \\
N1 & 1.056 & $0.972-1.146$ & 0.196 \\
N2 & 1.283 & $1.210-1.360$ & $<0.001$ \\
N3 & 1.324 & $1.240-1.413$ & $<0.001$
\end{tabular}

Marital status

Married

Unmarried

Bone metastasis

No

Yes

Brain metastasis

No

Yes

Liver metastasis

No

Yes

Lung metastasis

No

Yes

Liver metastasis prediction

Low total points $(\leq 86)$

High total points (>86)

*, other includes Native American/Alaska native, Asian/Pacific Islander, and unknown.
Ref

1.193

$1.149-1.240<0.001$

Ref

1.169

$1.103-1.239<0.001$

Ref

1.530

$1.459-1.640<0.001$

Ref

1.880

$1.799-1.964<0.001$

Ref

1.182

$1.115-1.254$

$<0.001$

Ref

10

1.103

1.037-1.172

0.002

American/Alaska native, Asian/Pacific


and clinicopathological factors that were easy to acquire in clinical practice. For those patients with SCLC who were not diagnosed with liver metastasis at the first detection, the nomogram might calculate the specific risk of subsequent distant metastasis by gathering the easily available information. Unlike imaging assessment measures, this easy-to-use nomogram could not only reduce the possible risk of radiation but also decrease individual medical expenses.

However, several key limitations of our study should be noted. In this study, both training and validation sets came from the SEER database, which could result in an overfitting model, and more independent external cohorts at other institutions are needed to validate the model. We did not include tumor genetic markers that might have potential to predict liver metastasis in patients with SCLC because they were unavailable in the SEER program. Furthermore, cases in this study were from the United States, and whether our model can be applied to the Asian population needs more researches.

To sum up, we constructed a brand novel predictive model to quantify the risk of liver metastasis in patients with SCLC. The nomogram might bring cancer patients fewer unnecessary examinations and lower medical expense, also it could provide clinicians with a new angle on treatment strategy decisions. However, several limitations of this study require future research.

\section{Acknowledgments}

Funding: This work was supported by the National Natural Science Foundation of China (grant numbers 81472199, 81472296, 81602091, 81402176, 81402093, 81272542, 81200369 ) and the National Natural Science Foundation of Jiangsu Province (grant number BK20141162).

\section{Footnote}

Reporting Checklist: The authors have completed the TRIPOD Checklist. Available at http://dx.doi. org/10.21037/apm-20-886

Data Sharing Statement: Available at http://dx.doi. org/10.21037/apm-20-886

Conflicts of Interest: All authors have completed the ICMJE uniform disclosure form (available at http://dx.doi. org/10.21037/apm-20-886). The authors have no conflicts of interest to declare.

Ethical Statement: The authors are accountable for all aspects of the work in ensuring that questions related to the accuracy or integrity of any part of the work are appropriately investigated and resolved. The study was conducted in accordance with the Declaration of Helsinki (as revised in 2013). All information from the SEER program is available and free for public, so the agreement of the medical ethics committee board was not necessary.

Open Access Statement: This is an Open Access article distributed in accordance with the Creative Commons Attribution-NonCommercial-NoDerivs 4.0 International License (CC BY-NC-ND 4.0), which permits the noncommercial replication and distribution of the article with the strict proviso that no changes or edits are made and the original work is properly cited (including links to both the formal publication through the relevant DOI and the license). See: https://creativecommons.org/licenses/by-nc-nd/4.0/.

\section{References}

1. Torre LA, Siegel RL, Jemal A. Lung Cancer Statistics. Adv Exp Med Biol 2016;893:1-19.

2. Siegel RL, Miller KD, Jemal A. Cancer statistics, 2019. CA Cancer J Clin 2019;69:7-34.

3. Fruh M, De Ruysscher D, Popat S, et al. Small-cell lung cancer (SCLC): ESMO Clinical Practice Guidelines for diagnosis, treatment and follow-up. Ann Oncol 2013;24 Suppl 6:vi99-105.

4. Kanis JA, Cooper C, Rizzoli R, et al. Executive summary of the European guidance for the diagnosis and management of osteoporosis in postmenopausal women. Calcif Tissue Int 2019;104:235-8.

5. Rudin CM, Poirier JT, Byers LA, et al. Author Correction: Molecular subtypes of small cell lung cancer: a synthesis of human and mouse model data. Nat Rev Cancer 2019;19:415.

6. Rodriguez-Canales J, Parra-Cuentas E, Wistuba II. Diagnosis and Molecular Classification of Lung Cancer. Cancer Treat Res 2016;170:25-46.

7. Sabari JK, Lok BH, Laird JH, et al. Unravelling the biology of SCLC: implications for therapy. Nat Rev Clin Oncol 2017;14:549-61.

8. Hayashi T, Takamochi K, Kohsaka S, et al. Transformation from EGFR/PTEN co-mutated lung adenocarcinoma to small cell carcinoma in lymph node metastasis. Pathol Int 
2020;70:295-9.

9. Wang PP, Liu SH, Chen CT, et al. Circulating tumor cells as a new predictive and prognostic factor in patients with small cell lung cancer. J Cancer 2020;11:2113-22.

10. Cronin KA, Ries LA, Edwards BK. The Surveillance, Epidemiology, and End Results (SEER) Program of the National Cancer Institute. Cancer 2014;120 Suppl 23:3755-7.

11. Van Schil PE, Rami-Porta R, Asamura H. The 8(th) TNM edition for lung cancer: a critical analysis. Ann Transl Med 2018;6:87.

12. Goldstraw P, Chansky K, Crowley J, et al. The IASLC Lung Cancer Staging Project: Proposals for Revision of the TNM Stage Groupings in the Forthcoming (Eighth) Edition of the TNM Classification for Lung Cancer. J Thorac Oncol 2016;11:39-51.

13. Pencina MJ, D'Agostino RB. Overall C as a measure of discrimination in survival analysis: model specific population value and confidence interval estimation. Stat Med 2004;23:2109-23.

14. Hanley JA, McNeil BJ. The meaning and use of the area under a receiver operating characteristic (ROC) curve. Radiology 1982;143:29-36.

15. Vickers AJ, Elkin EB. Decision curve analysis: a novel method for evaluating prediction models. Med Decis Making 2006;26:565-74.

16. Tas F, Aydiner A, Topuz E, et al. Factors influencing the distribution of metastases and survival in extensive disease small cell lung cancer. Acta Oncol 1999;38:1011-5.

17. Yao Y, Yang X, Sun L, et al. Fatty acid 2-hydroxylation inhibits tumor growth and increases sensitivity to cisplatin in gastric cancer. EBioMedicine 2019;41:256-67.

18. Ren Y, Dai C, Zheng H, et al. Prognostic effect of liver metastasis in lung cancer patients with distant metastasis. Oncotarget 2016;7:53245-53.

19. Nakazawa K, Kurishima K, Tamura T, et al. Specific organ metastases and survival in small cell lung cancer. Oncol Lett 2012;4:617-20.

20. Riihimaki M, Hemminki A, Fallah M, et al. Metastatic sites and survival in lung cancer. Lung Cancer 2014;86:78-84.

21. Garon EB, Reck M, Paz-Ares L, et al. Treatment Rationale and Study Design for the RELAY Study: A Multicenter, Randomized, Double-Blind Study of Erlotinib With Ramucirumab or Placebo in Patients With Epidermal Growth Factor Receptor Mutation-Positive Metastatic Non-Small-Cell Lung Cancer. Clin Lung Cancer 2017;18:96-9.
22. Schmid S, Diem S, Li Q, et al. Organ-specific response to nivolumab in patients with non-small cell lung cancer (NSCLC). Cancer Immunol Immunother 2018;67:1825-32.

23. Velez EM, Desai B, Ji L, et al. Comparative prognostic implication of treatment response assessments in mCRPC: PERCIST 1.0, RECIST 1.1, and PSA response criteria. Theranostics 2020;10:3254-62.

24. Zhang L, Xiang ZL, Zeng ZC, et al. A microRNAbased prediction model for lymph node metastasis in hepatocellular carcinoma. Oncotarget 2016;7:3587-98.

25. He C, Zhong L, Zhang Y, et al. Development and validation of a nomogram to predict liver metastasis in patients with pancreatic ductal adenocarcinoma: a large cohort study. Cancer Manag Res 2019;11:3981-91.

26. Shen J, Zhu M, Li S, et al. Incidence and Risk Factors for Suicide Death among Kaposi's Sarcoma Patients: A Surveillance, Epidemiology, and End Results Analysis. Med Sci Monit 2020;26:e920711.

27. Balachandran VP, Gonen M, Smith JJ, et al. Nomograms in oncology: more than meets the eye. Lancet Oncol 2015;16:e173-80.

28. Lim JH, Ryu JS, Kim JH, et al. Gender as an independent prognostic factor in small-cell lung cancer: Inha Lung Cancer Cohort study using propensity score matching. PLoS One 2018;13:e0208492.

29. Pesch B, Kendzia B, Gustavsson P, et al. Cigarette smoking and lung cancer--relative risk estimates for the major histological types from a pooled analysis of case-control studies. Int J Cancer 2012;131:1210-9.

30. Gu D, Wu X, Reynolds K, et al. Cigarette smoking and exposure to environmental tobacco smoke in China: the international collaborative study of cardiovascular disease in Asia. Am J Public Health 2004;94:1972-6.

31. Li J, Zhu H, Sun L, et al. Prognostic value of site-specific metastases in lung cancer: A population based study. J Cancer 2019;10:3079-86.

32. Cai H, Wang H, Li Z, et al. The prognostic analysis of different metastatic patterns in extensive-stage smallcell lung cancer patients: a large population-based study. Future Oncol 2018;14:1397-407.

33. Li J, Liu F, Yu H, et al. Different distant metastasis patterns based on tumor size could be found in extensivestage small cell lung cancer patients: a large, populationbased SEER study. PeerJ 2019;7:e8163.

34. Zhang Y, Sun Y, Chen H. Effect of tumor size on prognosis of node-negative lung cancer with sufficient lymph node examination and no disease extension. Onco 
Targets Ther 2016;9:649-53.

35. Zheng R, Yano S, Zhang H, et al. CD9 overexpression suppressed the liver metastasis and malignant ascites via inhibition of proliferation and motility of small-cell lung cancer cells in NK cell-depleted SCID mice. Oncol Res 2005; $15: 365-72$.

Cite this article as: Lu YJ, Yang Y, Yuan YH, Wang WJ, Cui MT, Tang HY, Duan WM. A novel nomogram based on SEER database for the prediction of liver metastasis in patients with small-cell lung cancer. Ann Palliat Med 2020;9(5):3123-3137. doi: 10.21037/apm-20-886
36. Kuramoto T, Goto H, Mitsuhashi A, et al. Dll4-Fc, an inhibitor of Dll4-notch signaling, suppresses liver metastasis of small cell lung cancer cells through the downregulation of the NF-kappaB activity. Mol Cancer Ther 2012;11:2578-87. 